\title{
Some immune parameters in carp Cyprinus carpio susceptible and resistant to the haemoflagellate Trypanoplasma borreli
}

\author{
J. P. Scharsack ${ }^{1}$, D. Steinhagen ${ }^{1, *}$, W. Körting ${ }^{1}$, B. Wagner ${ }^{2}$, W. Leibold ${ }^{2}$, \\ H. J. Schuberth ${ }^{2}$ \\ ${ }^{1}$ Fish Disease Research Unit, and ${ }^{2}$ Immunology Unit, School of Veterinary Medicine, Hannover, PO Box 711180, \\ 30545 Hannover, Germany
}

\begin{abstract}
The present study addresses aspects of the (specific) immune response of carp to the haemoflagellate Trypanoplasma borreli. Sera of resistant carp contained antibodies, which agglutinated the flagellates in vitro. When flagellates were incubated in fish sera from resistant carp, binding of antibodies to flagellates could be demonstrated by flow cytometry, and T. borreli were effectively killed. Heat-treatment of the sera prevented killing, indicating that complement activation is important for the control of a $T$. borreli infection. Sera of carp that were highly susceptible to infection with $T$. borreli contained no antibodies capable of binding to or killing the parasite. Furthermore, specific antibodies were not generated after experimental infection. This lack of antibody production in susceptible carp is not due to a general unresponsiveness of lymphoid cells, since peripheral blood leukocytes (PBL) from susceptible and resistant carp responded to mitogenic stimuli in vitro with lymphocyte proliferation in a similar manner. However, viable flagellates were significantly less able to stimulate proliferation of PBL from susceptible carp. In vitro-produced culture supernatants of freshly isolated PBL from both carp lines (but not those of head kidney cells) differentially modulated the mitogen-induced proliferation of PBL from susceptible and resistant carp. The supernatants enhanced the proliferation of leukocytes obtained from individuals from the same carp line, but suppressed the mitogen-induced proliferation of PBL from the other line tested. This indicates that lymphoid cells from susceptible and resistant carp differ in their spectrum of spontaneously produced immunomodulatory mediators. Whether this is decisive for a $T$. borreli-specific and successful immune response is discussed.
\end{abstract}

KEY WORDS: Trypanoplasma borreli $\cdot$ Disease susceptibility $\cdot$ Leukocyte activation · Immune modulation $\cdot$ Specific immune responses

\section{INTRODUCTION}

Kinetoplastid flagellates occur as extracellular blood parasites in the vascular system of a wide variety of different fishes. In European cyprinids, the trypanosomatid Trypanosoma carassii (formerly known as T. danilewskyi) and the bodonid Trypanoplasma borreli are widely distributed (Lom 1979, Lom \& Dykova 1992). They are transmitted by leeches, which leads to an initial rise in blood parasitaemia, followed by a decline in parasite numbers. Thereafter, low numbers of flagellates are present in the blood and internal organs of most fishes for a prolonged period. Chronic infections may result in a high prevalence of the flagellates in a fish population, but the intensity of infection is generally low (Lom 1979, Steinhagen et al. 1989, Lom \& Dykova 1992, Jones et al. 1993).

Infections with Trypanosoma carassii and Trypanoplasma borreli result in a characteristic non-fluctuating parasitaemia (Steinhagen et al. 1989, Overath et al. 1999). Fish that have controlled the acute infection are resistant against infection with lines of $T$. carassii or T. borreli, isolated from other carp in the chronic phase of infection (Overath et al. 1999, D.S. unpubl. obs.). Parasite-specific antibodies are believed to control these infections. They can be detected in the sera of 
infected fish (Lom \& Dykova 1992, Jones et al. 1993, Wiegertjes et al. 1995, 1996), and sera (or immunoglobin, IgM) of convalescent fish can transfer resistance to infection with T. carassii (Overath et al. 1999) to naive carp or can reduce the parasitaemia after a $T$. borreli infection (Wiegertjes et al. 1995). Complement fixing antibodies have also been observed to protect rainbow trout Oncorhynchus mykiss (Li \& Woo 1995, Feng \& Woo 1997) and Salvelinus fontinalis (Ardelli \& Woo 1997) from infection with Cryptobia salmositica, a haemoflagellate closely related to $T$. borreli. Plasma from naive $S$. namaycush, naturally resistant to $C$. salmositica, lysed the parasite in vitro, indicating that alternative complement activation might be the mechanism of resistance (Ardelli \& Woo 1997).

Some strains of carp were found to be highly susceptible to infection with Trypanoplasma borreli. Infection usually results in a $100 \%$ mortality 3 to 4 wk after injection of the flagellates. In the serum of these fish, parasite-specific antibodies could not be detected (Wiegertjes et al. 1995). In addition, these T. borrelisusceptible carp did not mount an antibody response to an unrelated antigen (dinitrophenyl-keyhole limpet haemocyanin, DNP-KLH). Thus it was considered that these carp might have a genetically predetermined low antibody response (Wiegertjes et al. 1995).

In mammalian trypanosomiasis, besides an antibody response, the state of macrophage activation is considered to be critical to trypanotolerance (Tabel et al. 2000, De Baetselier et al. 2001). Salivarian trypanosomes were able to induce an secretion of inflammatory molecules such as NO (nitric oxide), TNF (tumor necrosis factor) or IL1 (interleukin) by activated murine macrophages, which inhibited T-cell proliferative responses to parasite-related and -unrelated antigens (Schleifer \& Mansfield 1993, Sternberg 1998). In addition, De Baetselier et al. (2001) found that certain Trypanosoma brucei strains induced different, alternative cytokine patterns, which correlated with their pathogenicity.

In order to further characterise the role of a specific immune response for defence against Trypanoplasma borreli, we analysed serum from susceptible and resistant carp (collected after T. borreli challenge) for the ability to kill $T$. borreli and for the presence of T. borreli-specific immunoglobulin. In order to determine whether in the context of a $T$. borreli infection leukocyte-derived molecules suppress lymphocyte activation and thus might contribute to increased parasite susceptibility, we investigated the ability of $T$. borreli-stimulated head kidney leukocytes (HKL) and peripheral blood leukocytes (PBL) from carp strains of different parasite susceptibility to modulate lymphocyte activation in response to mitogens (pokeweed mitogen, PWM, and phytohaemagglutinin, PHA).

\section{MATERIALS AND METHODS}

Trypanoplasma borreli-susceptible carp and resistant pond carp. Susceptible carp: Carp of a single crossing $(\mathrm{E} 20 \times \mathrm{R} 8$, Wageningen Agricultural University, The Netherlands), susceptible to $T$. borreli infection, were bred and raised at 20 to $23^{\circ} \mathrm{C}$ in recirculated filtered tap water. After initial feeding with Artemia sp. nauplii for $4 \mathrm{wk}$, the food was switched to pelleted dry food (Milkivit). Carp, $2 \mathrm{yr}$ old and weighing 200 to $300 \mathrm{~g}$, were used for blood collection and infection with T. borreli. Before infection, the carp were acclimatised to a re-circulating system of separate $120 \mathrm{l}$ tanks at $20 \pm 1^{\circ} \mathrm{C}$ for at least $2 \mathrm{wk}$.

Resistant carp: We obtained 2 yr old carp (body weight 200 to $300 \mathrm{~g}$ ) from a hatchery in the vicinity of Hannover (Germany). The carp were selected from pond carp and transported to the laboratory, where groups of 20 fish were maintained in recirculated, filtered tap water at room temperature $\left(18\right.$ to $\left.20^{\circ} \mathrm{C}\right)$ in $300 \mathrm{l}$ tanks and fed daily with pelleted dry food (Milkivit). Carp were adapted to the maintenance conditions for at least $8 \mathrm{wk}$ before infection or leukocyte sampling. Trypanoplasma borreli flagellates in the circulating blood were never observed (checked microscopically at least 4 times), a previous infection with the blood flagellate, however, could not be excluded.

Infection experiments. Trypanoplasma borreli had previously been cloned and characterised, and was maintained in the laboratory by syringe passage as described earlier (Steinhagen et al. 1989). To check the carp for susceptibility to the $T$. borreli clone, 12 carp from each group were each injected intramuscularly (i.m.) with $1 \times 10^{4} \mathrm{~T}$. borreli in $100 \mu \mathrm{l}$ phosphate buffered saline (PBS). Every $2 \mathrm{wk}$ (up to $8 \mathrm{wk}$ postinfection), all carp were examined for the presence of T. borreli flagellates in the circulation: the fish were anaesthetised in $0.15 \mathrm{~g} \mathrm{l}^{-1}$ tricaine methane sulphonate (MS 222, Sigma-Aldrich); blood was collected from each carp by gill puncture with a glass capillary, transferred to glass slides and microscopically monitored for the presence of parasites.

For serum collection from infected carp, 3 resistant and 3 susceptible carp were injected intramuscularly with $1 \times 10^{4}$ Trypanoplasma borreli in $100 \mu \mathrm{l}$ PBS. Control carp (3 carp from both groups) were injected with $100 \mu \mathrm{l}$ PBS. Infected and control carp were kept under identical conditions. At Day 14 post-injection (p.i.), all carp were killed by immersion in $0.5 \mathrm{~g} \mathrm{l}^{-1}$ MS 222 . Whole blood was collected from the caudal vein and transferred to polystyrene tubes. The blood was kept at $22^{\circ} \mathrm{C}$ for $4 \mathrm{~h}$ followed by $48 \mathrm{~h}$ at $4^{\circ} \mathrm{C}$. After centrifugation $(15 \mathrm{~min}$ at $750 \times \mathrm{g}$ ), the serum was collected and the sera within the groups were pooled and kept frozen at $-80^{\circ} \mathrm{C}$ until use. For each fish, the para- 
sitaemia of $T$. borreli was determined by counting the flagellates present in the blood samples, using a Neubauer counting chamber.

Separation and blotting of carp serum proteins. Serum proteins were separated under reducing conditions by discontinuous sodium dodecyl sulphate polyacramide gel electrophoresis (SDS-PAGE) as described by Wagner et al. (1995). Sera were diluted 1:50 in sample buffer and $10 \mu \mathrm{l}$ were run per lane. Gels were either stained for proteins with Coomassie blue according to standard protocols (Sambrook et al. 1989) or blotted on PVDF-membranes (Millipore). Blots were incubated with the murine monoclonal antibody WCI 12 (specific for carp heavy-chain IgM; Secombes et al. 1983), and subsequently with a polyclonal goat anti mouse IgG $(\mathrm{H}+\mathrm{L})$ conjugated with alkaline phosphatase (Dianova). The substrate reaction was based on the method described by Blake et al. (1984).

Culture media. Culture media for cell separation and cultivation as well as PBS were diluted with distilled water $(10 \% \mathrm{v} / \mathrm{v})$ to adjust their osmotic pressure to carp serum osmolarity. Diluted RPMI 1640 (Biochrom) with $50000 \mathrm{IU} \mathrm{l}^{-1}$ sodium heparin (SigmaAldrich) was used for blood collection (heparinised medium). Diluted RPMI 1640 with 10000 IU l $^{-1}$ sodium heparin served as washing solution. For cultivation experiments, diluted RPMI was supplemented with $1 \%$ (v/v) 'carp serum' (leukocyte culture medium). Carp serum was a pool of heat-treated $\left(30 \mathrm{~min}, 56^{\circ} \mathrm{C}\right.$ ) and sterile-filtered $(0.2 \mu \mathrm{m})$ sera from 15 individual fish.

Trypanoplasma borreli were raised in a mixture of Hanks buffered salt solution (42.5\%, v/v), Earl's modified minimum essential medium $(21.25 \%$, v/v), Leibovitz 15 medium (21.25\%, v/v), distilled water (10\%, v/v) and $5 \%$ carp serum (HML medium, Steinhagen et al. 2000). All culture media were supplemented with $100000 \mathrm{IU} / \mathrm{L}$ penicillin, $100 \mathrm{mg} \mathrm{l}^{-1}$ streptomycin and $4 \mathrm{mM}$ L-glutamine (all chemicals: Biochrom).

Detection of Trypanoplasma borreli-specific immunoglobulin in carp serum. Viable T. borreli flagellates $\left(2 \times 10^{5}\right.$ well $^{-1}$, 96-well, round-bottomed microtitre plate) were incubated for $30 \mathrm{~min}$ at $4{ }^{\circ} \mathrm{C}$ in the presence of sera pooled from 3 resistant or 3 susceptible carp. Sera were diluted with PBS (1:10; 1:100; $1: 1000 ; 1: 10000)$. All set-ups were made in duplicate. After 2 washings with $\mathrm{PBS}$ at $4^{\circ} \mathrm{C}(10 \mathrm{~min}, 550 \times g)$, the flagellates were resuspended and incubated for $30 \mathrm{~min}$ on ice with the murine monoclonal antibody WCI 12 (see earlier subsection). This was followed by 2 washings with PBS and incubation with a fluorescein isothiocyanate (FITC)-labelled rabbit anti-mouse Ig (1:160, DAKO) for 30 min on ice. After 3 washings with PBS, fluorescence of $T$. borreli flagellates was determined by flow cytometry recording the percentage of labelled $T$. borreli and the mean fluorescence intensity of stained flagellates.

Leukocyte isolation. Blood was collected into syringes prefilled with heparinised medium by caudal vein puncture. Peripheral blood leukocytes (PBL) were separated from erythrocytes by centrifugation (30 min, $750 \times g$ ) over Lymphoprep (Nycomed) as described by Miller \& McKinney (1994). Media and cells were kept on ice and washing procedures were performed at $4^{\circ} \mathrm{C}$. Cell suspensions of head kidney leukocytes (HKL) were prepared by forcing the tissues through nylon mesh (100 $\mu \mathrm{m}$, Swiss Silk Bolting Cloth Mfg). Isolated PBL and HKL were washed 3 times with wash medium $(10 \min , 550 \times g)$ and resuspended in cell culture medium. Numbers of viable cells were determined by trypan blue exclusion in a cell-counting chamber.

Preparation of Trypanoplasma borreli. T. borreli cultured for at least 6 wk were washed with leukocyte culture medium and were adjusted to the required concentration (see following subsection). For preparation of lysates, the $T$. borreli concentration was adjusted to $2 \times 10^{8}$ flagellates $\mathrm{ml}^{-1}$ in leukocyte culture medium. Then the suspensions were sonicated for $30 \mathrm{~s}$ at $15 \mu \mathrm{m}$ in an Ultrasonic Disintegrator (MSE) on ice. T. borreli lysates were stored at $-80^{\circ} \mathrm{C}$ until use.

Leukocyte cultivation. For proliferation experiments, peripheral blood leukocytes were incubated in 96 -well flat bottomed microtitre plates $\left(10^{6}\right.$ cells well $^{-1}$ in a final volume of $175 \mu$ l leukocyte culture medium for $4 \mathrm{~d}$ at $27^{\circ} \mathrm{C}$ in water vapour-saturated atmosphere with $3 \% \mathrm{CO}_{2}$ ). All set-ups were in triplicate. PBL were stimulated with pokeweed mitogen (PWM; $1 \mathrm{mg} \mathrm{l}^{-1}$ ), phytohaemagglutinin ( $\mathrm{PHA}_{i} 3 \mathrm{mg} \mathrm{l}^{-1}$ ), and viable or lysed Trypanoplasma borreli $\left(5 \times 10^{5}\right.$ well $\left.^{-1}\right)$.

For the preparation of culture supernatants (SN) PBL and HKL $\left(5 \times 10^{6} \mathrm{ml}^{-1}\right)$ from susceptible and resistant carp were incubated in 24-well flat-bottomed plates in a final volume of $1 \mathrm{ml}$ well ${ }^{-1}$ for $4 \mathrm{~d}$. Parallel set-ups contained cells together with $2.5 \times 10^{6}$ viable Trypanoplasma borreli $\mathrm{ml}^{-1}$ or $2.5 \times 10^{6}$ viable $T$. borreli $\mathrm{ml}^{-1}$ alone. All assays were made with cells of 3 resistant and 3 susceptible carp. The culture supernatants of individual set-ups were pooled, centrifuged (15 min, $750 \times g$ ) and stored at $-80^{\circ} \mathrm{C}$ until use.

Flow cytometry analysis of cultured cells. Suspensions of carp leukocytes (PBL, HKL) and Trypanoplasma borreli were analysed with a FACScan ${ }^{\circledR}$ (Becton Dickinson, single excitation wavelength of $488 \mathrm{~nm}$ ). Cellular subsets were identified according to their characteristic forward and side-scatter values (FSC/SSC profiles; Verburg-Van Kemenade et al. 1994, Scharsack et al. 2000). Propidium iodide (2 $\mathrm{mg} \mathrm{l}^{-1}$ final conc.) was added to the suspensions to label membrane-damaged cells. At least 10000 events were acquired and analysed with the software WinMDI, 
a)

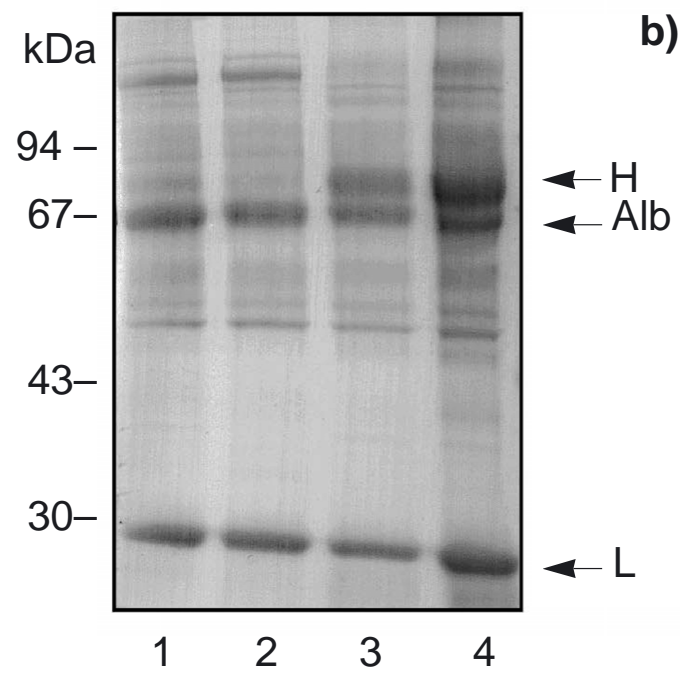

b)

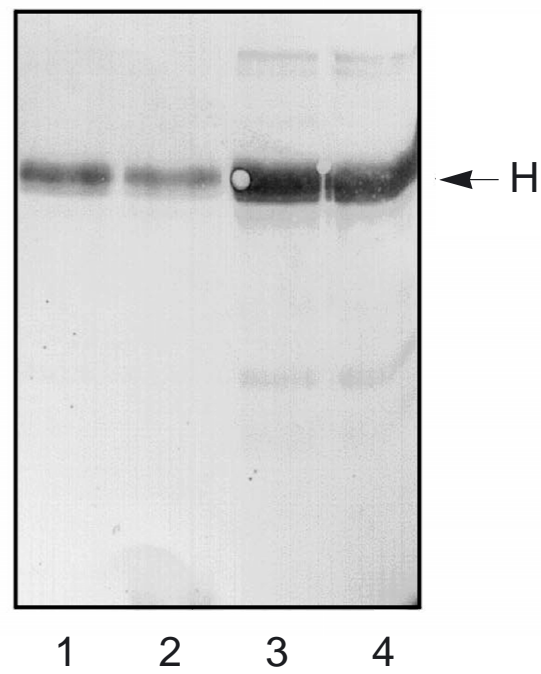

Fig. 1. Cyprinus carpio. SDS-PAGE and immunoblotting of serum proteins from susceptible and resistant carp. (a) Coomassie blue-stained gel; (b) immunoblot of separated serum proteins with Antibody WCI 12 (anti-carp immunoglobulin heavy chains). Lane 1: serum from susceptible, PBS-injected carp; Lane 2: serum from susceptible, T. borreli-injected carp; Lane 3: serum from resistant, PBS-injected carp; Lane 4: serum from resistant, T. borreli-injected carp; arrows denote positions of immunoglobulin heavy $(\mathrm{H})$ and presumably light ( $\mathrm{L}$, as judged from molecular weight) chains and of albumin (Alb)

Version 2.8 (Trotter 1998: WinMDI 2.8 software package; www.facs.scripps.edu/software.html). Cellular debris with low FSC characteristics and dead cells were excluded from further evaluation.

Total cell numbers were determined with the singlecell dilution assay (Pechhold et al. 1994) using bovine, FITC-labelled PBL as standard cells (Hendricks et al. 2000). Numbers (N) of cultivated cells in individual wells were calculated according to: $\mathrm{N}$ [viable cells] = events[viable cells] $\times \mathrm{N}$ [standard cells]/events[standard cells].

Statistics. Data sets were compared by ANOVA and Duncan's multiple-range tests. Differences with $\mathrm{p}<$ 0.05 were considered significant.

\section{RESULTS}

\section{Infection experiments}

All 12 susceptible carp showed parasitaemia and died between 21 to $25 \mathrm{~d}$ after infection with Trypanoplasma borreli flagellates. In contrast, T. borreliinjected pond carp $(n=12)$ did not show any sign of parasitaemia throughout the observation period of $8 \mathrm{wk}$.

Sera were taken at Day 14 post-infection. The pooled sera of both susceptible and resistant carp appeared to contain some immunoglobulins, and in both groups infection with Trypanoplasma borreli did not result in a change in the total serum imunoglobulin concentration (Fig. 1, cf. Lane 1 with Lane 2 or Lane 3 with 4).
Striking differences appeared when the sera were tested for Trypanoplasma borreli-specific antibodies by incubation with live $T$. borreli flagellates. Sera from PBS-injected, resistant carp already contained $T$. borreli-reactive antibodies (Fig. 2), which may indicate previous infection with the parasite. The higher fluorescence intensity at lower serum dilution and the higher fraction of stained T. borreli flagellates (Fig. 2) indicates that specific antibodies were boosted after infection of resistant carp with $T$. borreli. In contrast, no reactivity of serum antibodies from PBS-injected or T. borreli-infected susceptible carp with the flagellates was detectable (Fig. 2).

Incubation of Trypanoplasma borreli with serum from challenged as well as non-challenged pond carp killed the parasites after $18 \mathrm{~h}$ in vitro (Table 1). This trypanocidal activity of the sera disappeared after heat treatment of the sera. This could indicate that complement activity is involved in the killing of trypanoplasms in vivo. The viability of $T$. borreli was not affected by sera of susceptible carp (Table 1).

\section{In vitro responses of head kidney leukocytes and peripheral blood leukocytes from carp resistant and susceptible to Trypanoplasma borreli}

The inability of susceptible carp to produce antibodies after infection with Trypanoplasma borreli was not due to a general inability of peripheral blood leukocytes to respond to mitogens (PWM, PHA) with proliferation (Fig. 3). Also the blastogenesis in response to 


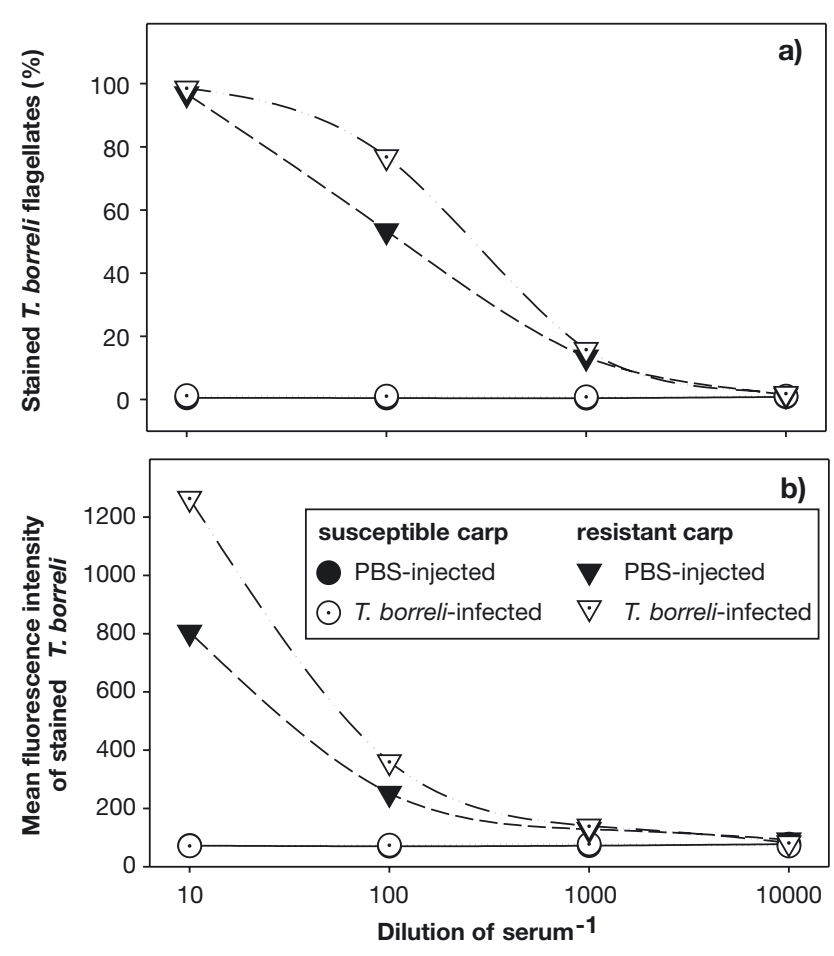

Fig. 2. Cyprinus carpio. Presence of Trypanoplasma borrelireactive carp immunoglobulins in sera from susceptible and resistant carp. (a) Fraction of immunoglobulin-positive cells and (b) mean fluorescence intensity

lysed $T$. borreli preparations was comparable between PBL of resistant and susceptible carp (Fig. 3). However, differences were apparent when PBL were cultured in the presence of viable flagellates: PBL from resistant carp responded with blastogenesis in a magnitude comparable with PHA-stimulated PBL, whereas the response of PBL from susceptible carp towards viable T. borreli was significantly lower (Fig. 3).

A Trypanoplasma borreli-induced proliferative response of PBL from resistant carp was also observed with cell-free culture supernatants (SNs) of the flagellates (Fig. 4, Set-up 2). Again, the responses of PBL from susceptible carp were not modulated by SNs from T. borreli (Fig. 4, Set-up 1).

Differences in the responsiveness of PBL from both carp groups could be due to a different range of secreted mediators. We therefore cultivated PBL of resistant and susceptible carp and tested the cellfree supernatants for their modulatory potential in stimulation assays.

While SNs of PBL from resistant carp clearly enhanced the PWM- and PHA-induced blastogenesis of PBL from resistant carp, this effect was significantly less apparent with PBL from susceptible carp (cf. Set-ups 3 and 4, Fig. 4). Interestingly, SNs from cultured PBL of susceptible carp enhanced the pro-
Table 1. Cyprinus carpio, infected with Trypanoplasma borreli. Survival (viable T. borreli per well $\times 10^{5}$ ) of $T$. borreli after incubation with serum from susceptible or resistant carp. Values are means \pm SD of triplicate cultures

\begin{tabular}{|lcc|}
\hline Serum source & $\begin{array}{c}\text { Native } \\
\text { serum }\end{array}$ & $\begin{array}{c}\text { Heat-treated } \\
\text { serum }\end{array}$ \\
\hline Susceptible carp & & \\
PBS-injected & $3.7 \pm 0.3$ & $3.6 \pm 0.2$ \\
T. borreli-infected & $3.8 \pm 0.3$ & $3.7 \pm 0.1$ \\
Resistant carp & & \\
PBS-injected & $0.8 \pm 0.04$ & $3.7 \pm 0.1$ \\
T. borreli-infected & $0.05 \pm 0.02$ & $3.8 \pm 0.2$ \\
None (medium control) & \multicolumn{2}{c}{$3.6+0.2$} \\
\hline
\end{tabular}

liferative response of PBL from susceptible carp, however, the PHA-induced response of PBL of resistant carp was only slightly enhanced, and the PWMinduced response was even diminished (cf. Set-ups 5 and 6, Fig. 4).

The differential modulatory capacities of SNs from cultured PBL indicate that the cells of resistant and susceptible carp produce a different range of soluble mediators.

This was further substantiated when SNs which were produced by PBL in the presence of Trypanoplasma borreli were tested. SNs of resistant carp stimulated or enhanced the proliferative response of PBL from resistant carp, but not that of PBL from susceptible carp (cf. Set-ups 7 and 8, Fig. 4). Interestingly, SNs from PBL of susceptible carp increased the proliferative response of both $\mathrm{PBL}$ from resistant carp and that of PBL from susceptible carp (cf. Set-ups 9 and 10, Fig. 4).

In contrast to PBL, HKL of susceptible and resistant carp did not differ much in their spectrum of secreted

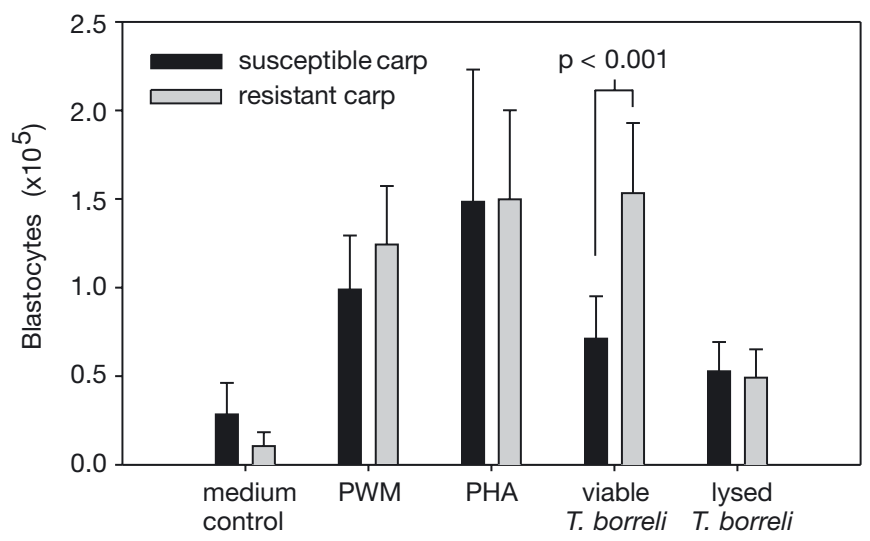

Fig. 3. Cyprinus carpio. Proliferative response of peripheral blood leukocytes from susceptible and resistant carp. All setups were in triplicate. Total numbers of blastocytes (means $+\mathrm{SD}$ of 3 fish) were quantified by flow cytometry 


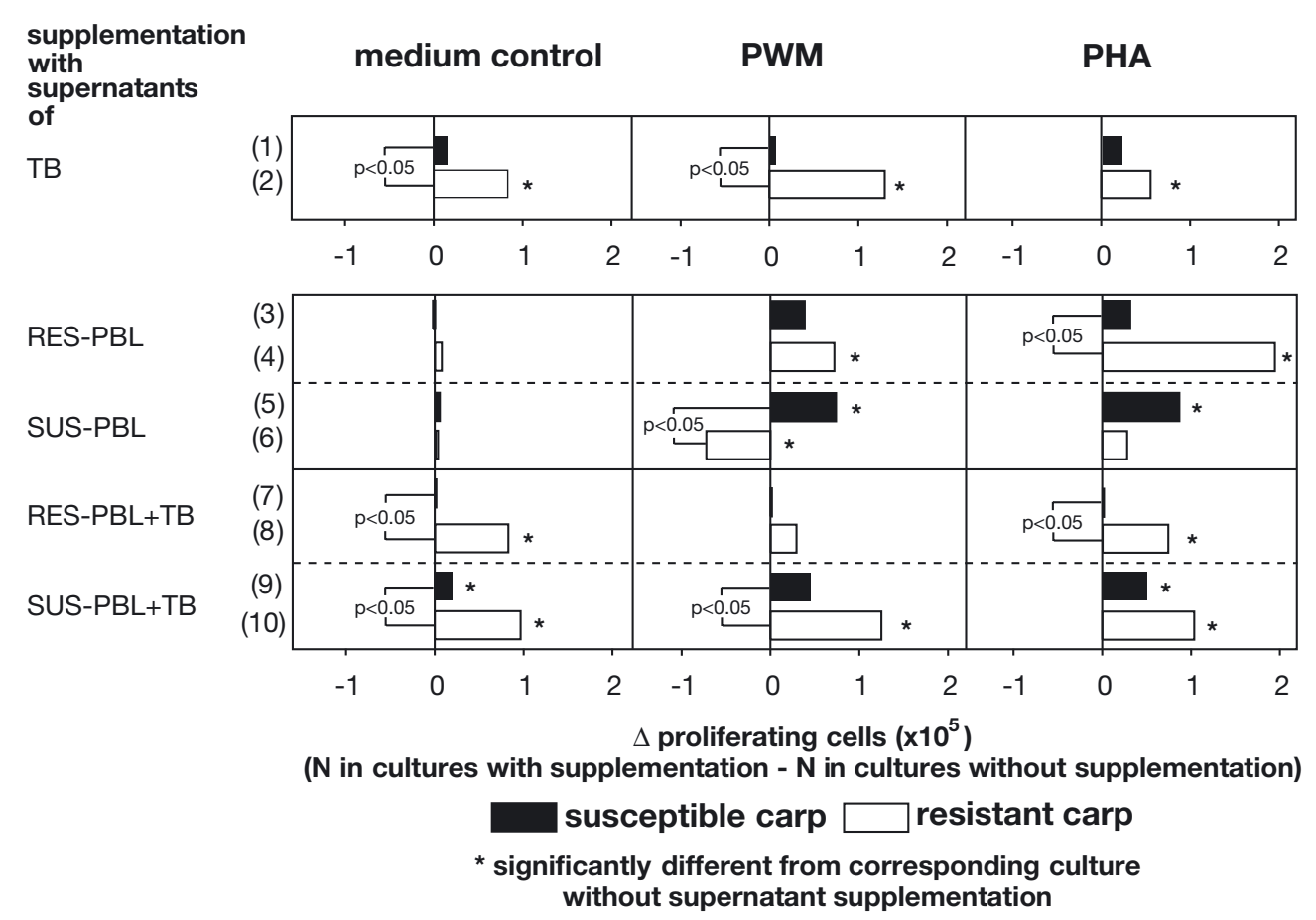

Fig. 4. Cyprinus carpio. Influence of Trypanoplasma borreli-conditioned culture supernatants on proliferative response of peripheral blood leukocytes (PBL) from susceptible and resistant carp. Peripheral blood leukocytes $\left(1 \times 10^{6}\right.$ well $\left.{ }^{-1}\right)$ from susceptible $(\mathrm{n}=$ 3 ) and resistant $(\mathrm{n}=3)$ carp were cultured for $4 \mathrm{~d}$ in vitro in presence of mitogens (pokeweed mitogen, PWM, 1 mg l-1; phytohaemagglatinin, PHA, $3 \mathrm{mg} \mathrm{l}^{-1}$ ). All set-ups (1 to 10) were made in triplicate. Parallel set-ups were supplemented with supernatants of in vitro-cultured T. borreli (TB), with supernatants of in vitro-cultured PBL. PBL were from susceptible (SUS-PBL) or resistant (RES-PBL) carp. Also, supernatants of PBL cultured in presence of $T$. borreli were added to mitogen-stimulated cell cultures (RES-PBL+TB; SUS-PBL+TB). p values indicate significant differences between divergent carp lines. Total numbers of blastocytes were quantified by flow cytometry. Data are numbers of blastocytes $\left(\times 10^{5}\right)$ after subtracting numbers of blastocytes from corresponding control cultures (without supernatant supplementation)

and modulating mediators: HKL supernatants of both carp lines suppressed the mitogen-induced proliferation of PBL from susceptible carp (especially the PWMinduced proliferation; data not shown). Also, when HKL were cultivated in the presence of Trypanoplasma borreli, the supernatants of cells of both carp lines suppressed the cellular proliferation of PBL from resistant or susceptible carp largely to the same degree (data not shown).

\section{DISCUSSION}

Carp susceptible to an infection with Trypanoplasma borreli died after experimental infection. Sera from this strain of carp contained no detectable antibodies, either before or after infection. Despite the limited number of individuals analysed here, these results support previous findings (Jones et al. 1993, Wiegertjes et al. 1995), which suggested that generation of a specific immune response is decisive for effective elimination of $T$. borreli.

In contrast, the pond-reared carp contained antibodies both before and after experimental infection.
Heat-labile factors, most probably complement, were responsible for effectively killing the parasite in vitro. As the parasite was killed in the presence of antibodies binding to Trypanoplasma borreli, complement activation by the classical pathway could be suspected. Complement activity also was observed to be important in the protection of salmonid fish from infections with Cryptobia salmositica. In rainbow trout infected with C. salmositica, complement-fixing antibodies were shown to be the key mechanisms combating the infection (Li \& Woo 1995, Feng \& Woo 1997), while in Salvelinus namaycush, a fish species with natural resistance to $C$. salmositica complement activated via the alternative pathway mediated the destruction of the parasites (Ardelli \& Woo 1997). Our experiments cannot exclude a possible role of alternatively activated complement in resistance of carp to $T$. borreli infection, but the complete lack of trypanocidal activity in serum from susceptible carp suggests that in serum from these carp, complement activation was not via the alternative pathway in the presence of $T$. borreli.

The 2 different carp strains investigated here did not only differ in genetic background, but also in life history. While carp susceptible to the flagellate were 
grown under laboratory conditions, the resistant carp were obtained from a local hatchery. Thus differences of the fish groups in their response to Trypanoplasma borreli besides their different genetic background might be influenced by their different life histories as well.

The reason for the lack of antibody response in susceptible carp is still unclear. Serum samples for the present investigation were collected on Day 14 p.i. Upon injection of sheep red blood cells (SRBC), carp showed a placque-forming cell response which peaked on Day 12 p.i. when the fish were kept at $20^{\circ} \mathrm{C}$, and on Day 9 at $24^{\circ} \mathrm{C}$ (Rijkers et al. 1980). In the present study, carp were kept at $20^{\circ} \mathrm{C}_{i}$ thus the presence of some antibodies might be expected in their serum by $14 \mathrm{~d}$ post-infection with the parasite. However, Wiegertjes et al. (1995) could not detect antibodies to Trypanoplasma borreli or to an antigen unrelated to the parasite (DNP-KLH) in the serum of individuals from the same carp line even $21 \mathrm{~d}$ p.i. Therefore, Wiegertjes et al. (1995) suggested a more general Bcell anergy in these carp. However, when peripheral blood lymphocytes (PBL) were stimulated in vitro, cells of both resistant and susceptible carp responded with blastogenesis after mitogenic stimulation in a comparable manner. Previously, we also showed in blood, head kidney and spleen of $T$. borreli-infected susceptible carp the presence of many lymphoblasts, among which surface immunoglobulin-positive B-cells occurred (Barckhausen-Kiesecker 1995, Scharsack et al. 2000). In addition, sera from susceptible carp contained detectable amounts of heavy-chain Ig, indicating a general ability of susceptible carp to produce Ig.

Although we did not check in this study whether B-cells were activated or not, a Trypanoplasma borreliinduced proliferation of PBL could be observed in susceptible carp (Scharsack et al. 2000, 2003a). However, cells of susceptible carp proliferated significantly less in response to viable $T$. borreli compared to cells from resistant carp. This could be due to a memory effect in resistant carp resulting from a previous pond infection with $T$. borreli. In serum from resistant carp, considerable amounts of $T$. borreli-specific antibodies were detected, even before infection under laboratory conditions. Nevertheless, infection with $T$. borreli resulted in a boosting of Ig production in resistant carp, while in infected susceptible carp no $T$. borreli-specific Ig was detectable.

If B-cells of susceptible carp are not anergic and are stimulated by Trypanoplasma borreli in vivo (Barckhausen-Kiesecker 1995) and in vitro, the inability of susceptible carp to mount an Ig response could be related to an insufficient modulatory impact.

One possible explanation could be a lack of an appropriate mediator production by accessory mono- cytic cells. This is supported by observations in mammals infected with salivarian trypanosomes (e.g. Trypanosoma brucei), whereby the state of macrophage activation was considered to be critical for trypanotolerance and macrophage-derived inflammatory mediators interfered with lymphocyte responses (Schleifer \& Mansfield 1993, Tabel et al. 2000, De Baetselier et al. 2001). However, we have previously shown that head kidney leukocytes of both carp lines do not differ in their ability to generate immunomodulatory nitric oxide (NO) or other reactive oxygen species (Scharsack et al. 2003a,b). Moreover, supernatants of Trypanoplasma borreli-stimulated head kidney leukocyte cultures from susceptible and resistant carp did not differ in their modulatory capacity for the proliferative response of PBL from both carp lines to mitogens (data not shown). Thus, $T$. borreli seems to activate monocytic cells from both carp lines in a similar manner.

In carp infected with Trypanoplasma borreli, signals from lymphocyte subsets might play a more important role in B-cell activation and Ig production. In the present study, indirect evidence that lymphocytes from the 2 carp lines differ in their secreted pattern of mediators was gained by experiments in which PBL supernatants were tested for their modulatory capacity on mitogeninduced PBL proliferation. For example, supernatants of PBL from resistant carp enhanced the PWM-induced proliferation of resistant carp PBL, whereas supernatants of susceptible carp PBL suppressed this response.

In addition, lymphocytes from the 2 carp lines are obviously different in the pattern of receptors responsible for the recognition of mediator substances. In cultures with supernatants of PBL from resistant carp, enhancement of the PHA-induced proliferation was significantly higher with PBL from resistant carp.

Supernatants of PBL from susceptible carp enhanced the PWM response of PBL from this carp line, while the PWM response of PBL from resistant carp was suppressed. This might indicate that both the pattern of mediators released and the pattern of receptors for modulatory molecules, present on lymphocyte subsets, influence the generation of an effective humoral response to Trypanoplasma borreli.

Taken together, the inability of $T$. borreli-susceptible carp to mount a humoral response against the parasite, as reported by Wiegertjes et al. (1995), is most likely not due to a general B-cell anergy. Head kidney leukocytes of susceptible and resistant carp responded to $T$. borreli in vitro in a comparable manner, and released a pattern of mediators that influenced lymphocyte proliferation of both carp lines in the same way.

In vivo, a strong lymphocyte activation was observed in susceptible carp after Trypanoplasma borreli infection (Scharsack et al. 2000, 2003a). In Trypano- 
soma cruzi infection in man, abrogation or reduction of a strong polyclonal lymphocyte activation correlates with an increased resistance to infection (cf. Minoprio 2001). In a similar way, the differences between the carp lines in susceptibility to $T$. borreli could be based on a strong polyclonal activation, which is not downregulated by appropriate inhibitory signals provided by yet unidentified cellular lymphoid subsets.

\section{LITERATURE CITED}

Ardelli BF, Woo PTK (1997) Protective antibodies and anamnestic response in Salvelinus fontinalis and innate resistance of Salvelinus namaycush to the hemoflagellate. J Parasitol 83:943-946

Barckhausen-Kiesecker I (1995) Untersuchung lymphoider Organe von Karpfen (Cyprinus carpio L.) im Verlauf parasitärer Infektionen. Dr. med. vet. thesis, Hannover School of Veterinary Medicine, Hannover

Blake MS, Johnston KH, Russel-Jones GL, Gotschlich EC (1984) A rapid, sensitive method for detection of alkaline phosphatase-conjugated antibody on Western blots. Anal Biochem 136:175-179

De Baetselier PD, Namangala B, Noel W, Brys L, Pays E, Beschin A (2001) Alternative versus classical macrophage activation during experimental African trypanosomosis. Int J Parasitol 31:574-586

Feng S, Woo PTK (1997) Complement fixing antibody production in thymectomized Oncorhynchus mykiss, vaccinated against or infected with the pathogenic haemoflagellate Cryptobia salmositica. Folia Parasitol (České Budějovice) 44:188-194

Hendricks A, Leibold W, Kaever V, Schuberth HJ (2000) Prostaglandin E2 is variably induced by bacterial superantigens in bovine mononuclear cells and has a regulatory role for the $\mathrm{T}$ cell proliferative response. Immunobiology 201:493-505

Jones SRM, Palmen M, van Muiswinkel WB (1993) The effects of inoculum route and dose on the immune response of common carp, Cyprinus carpio to the blood parasite, Trypanoplasma borreli. Vet Immunol Immunopathol 36:369-378

Li S, Woo PTK (1995) Efficiacy of a live Cryptobia salmositica vaccine, and the mechanism of protection in vaccinated rainbow trout, Oncorhynchus mykiss, against cryptobiosis. Vet Immunol Immunopathol 48:343-353

Lom J (1979) Biology of trypanosomes and trypanoplasms of fish. In: Lumsden WHR, Evans DA (eds) Biology of the Kinetoplastida, Vol 2. Academic Press, London p 269-337

Lom J, Dykova I (1992) Protozoan parasites of fishes. Dev Aquac Fish Sci 26:1-315

Miller NW, McKinney EC (1994) In vitro culture of fish leukocytes. In: Hochachka PW, Mommsen TP (eds) Biochemistry and molecular biology of fishes, 3 . Elsevier, Amsterdam, p 341-353

Minoprio P (2001) Parasite polyclonal activators: new targets for vaccination approaches? Int J Parasitol 31:587-590

Overath P, Haag J, Mameza MG, Lischke A (1999) Freshwater fish trypanosomes: definition of two types, host control by antibodies and lack of antigenic variation. Parasitology 119:591-601
Pechhold K, Pohl T, Kabelitz D (1994) Rapid quantification of lymphocyte subsets in heterogenous cell populations by flow cytometry. Cytometry 16:152-159

Rijkers GT, Fredrix-Wolters EM, van Muiswinkel WB (1980) The immune system of cyprinid fish: kinetics and temperature dependence of antibody-producing cells in carp (Cyprinus carpio). Immunology 41:91-97

Sambrook J, Fritsch EF, Maniatis T (1989) Molecular cloning: a laboratory manual. Cold Spring Harbor Laboratory Press, New York

Scharsack JP, Steinhagen D, Körting W, Leibold W, Schuberth HJ (2000) Flow cytometric analysis of proliferative responses of carp (Cyprinus carpio) peripheral blood leukocytes to mitogens and to the haemoflagellate Trypanoplasma borreli. Dis Aquat Org 41:203-210

Scharsack JP, Steinhagen D, Kleczka C, Schmidt JO, Körting W, Michael RD, Leibold W, Schuberth HJ (2003a) The haemoflagellate Trypanoplasma borreli induces the production of nitric oxide, which modulates carp (Cyprinus carpio L.) leukocyte functions. Fish Shellfish Immunol 14: 207-222

Scharsack JP, Steinhagen D, Kleczka C, Schmidt JO, Körting W, Michael RD, Leibold W, Schuberth HJ (2003b) Head kidney neutrophils of carp (Cyprinus carpio L.) are functionally modulated by the haemoflagellate Trypanoplasma borreli. Fish Shellfish Immunol 14:389-403

Schleifer KW, Mansfield JM (1993) Suppressor macrophages in African trypanosomiasis inhibit $\mathrm{T}$ cell proliferative responses by nitric oxide and prostaglandins. J Immunol 151:5492-5503

Secombes CJ, Groningen JJM van, Egberts E (1983) Separation of lymphocyte subpopulations in carp (Cyprinus carpio L.) by monoclonal antibodies: immunohistochemical studies. Immunology 48:165-175

Steinhagen D, Kruse P, Körting W (1989) The parasitaemia of cloned Trypanoplasma borreli Laveran \& Mesnil, 1901 in laboratory-infected common carp (Cyprinus carpio). J Parasitol 75:685-689

Steinhagen D, Heddereich W, Skouras A, Scharsack JP, Leibold W, Schuberth HJ, Körting W (2000) In vitro cultivation of Trypanoplasma borreli (Protozoa: Kinetoplastida), a parasite from the blood of common carp, Cyprinus carpio. Dis Aquat Org 41:195-201

Sternberg JM (1998) Immunobiology of African trypanosomiasis. Chem Immunol 70:186-199

Tabel H, Kaushik RS, Uzonna JE (2000) Susceptibility and resistance to Trypanosoma congolense-infections. Microbes Infect 2:1619-1629

Verburg-Van Kemenade BM, Groeneveld A, Van Rens BTTM, Rombout JHWM (1994) Characterisation of macrophages and neutrophilic granulocytes from the pronephros of carp (Cyprinus carpio). J Exp Biol 187:143-158

Wagner B, Radbruch A, Richards C, Leibold W (1995) Monoclonal equine IgM and IgG immunoglobulins. Vet Immun Immunopathol 47:1-12

Wiegertjes GF, Groeneveld A, van Muiswinkel WB (1995) Genetic variation in susceptibility to Trypanoplasma borreli infection in common carp (Cyprinus carpio L.). Vet Immunol Immunopathol 47:153-61

Wiegertjes GF, Bongers AB, Voorthuis P, Zandieh Doulabi B, Groeneveld A, Van Muiswinkel WB, Stet RJ (1996) Characterisation of isogenic carp (Cyprinus carpio L.) lines with a genetically determined high or low antibody production. Anim Genet 27:313-319 